\title{
Effects of Fe Addition on the Snoek-Type Damping Behavior of Surface-Oxidation-Treated Ti-Mo Alloys
}

\begin{abstract}
HUI LU, CHUNXIA LI, FUXING YIN, QIANFENG FANG, and OSAMU UMEZAWA
Effects of Fe addition on the oxygen diffusion and the Snoek-type relaxation damping behavior of the Ti-15 wt pct Mo alloy were investigated in this study. After surface oxidation treatment, the Ti-15 wt pet Mo-1 wt pet Fe alloy exhibits a higher damping capacity compared to the Ti-15 wt pct Mo alloy. The dual-phase zone and the oxygen-enriched $\beta$-phase zone in the surface-oxidation-treated Ti-Mo alloys were determined by electron backscattered diffraction (EBSD) and hardness measurements. Based on the oxygen distributions in both alloys obtained through a diffusion model, the relative damping capacity of different zones contributing to the beam sample damping was estimated to be proportional to the thickness of the oxygen dissolved zones. On the other hand, the substitutional solute of $\mathrm{Fe}$ in the Ti-Mo-Fe alloy is considered to affect the oxygen distribution by lengthening the oxygen diffusion zone and increasing the oxygen concentration in this zone. As a result, the addition of Fe in Ti-Mo alloy improves the damping capacity of the surface-oxidation-treated alloys.
\end{abstract}

DOI: $10.1007 / \mathrm{s} 11661-011-0616-0$

(C) The Minerals, Metals \& Materials Society and ASM International 2011

\section{INTRODUCTION}

SNOEK relaxation, i.e., the anelastic relaxation caused by interstitial solute atoms in body-centeredcubic (bcc) metals, has been widely investigated in many bcc metals, such as $\mathrm{Fe}, \mathrm{Nb}, \mathrm{Ta}$, and $\mathrm{V}^{[1,2]}$ The Snoek relaxation in substitutional alloys is often modified by the interaction between substitutional solutes and interstitial solutes in alloys, and this type of relaxation is usually called Snoek-type relaxation. ${ }^{[3]}$ Recently, Yin et al. ${ }^{[4,5]}$ applied the Snoek-type relaxation mechanism to the Ti-Nb alloys containing a high concentration of oxygen, in order to design a new type of high damping alloys with both the high strength and high damping capacity. Ti-Mo alloys and $\mathrm{Ti}-\mathrm{Nb}$ alloys share some common mechanical properties with $\beta$ Ti alloys, such as high strength, low modulus, suitable ductility, and superior workability for engineering application. Compared with $\mathrm{Nb}, \mathrm{Mo}$ is a more effective $\beta$-phase stabilizing element for Ti alloys, because the equivalent Mo content efficient to suppress the $\beta \rightarrow \alpha^{\prime \prime}$ martensitic transformation to a temperature below room temperature is $\mathrm{Mo}_{e q}$ $($ mass pct $)=1.0 \mathrm{Mo}+0.28 \mathrm{Nb}+2.9 \mathrm{Fe}+\ldots{ }^{[6]}$

HUI LU, Doctoral Student, Exploratory Materials Research Laboratory for Reliability and Safety, National Institute for Materials Science, Tsukuba, 305-0047, Japan, and Key Laboratory of Materials Physics, Institute of Solid State Physics, Hefei, 230031, P.R. China. Contact e-mail: luhui@mail.ustc.edu.cn CHUNXIA LI, Doctoral Student, and OSAMU UMEZAWA, Professor, are with the Faculty of Engineering, Yokohama National University, Yokohama, 240-8501, Japan. FUXING YIN, Chief Researcher, is with the Exploratory Materials Research Laboratory for Reliability and Safety, National Institute for Materials Science. QIANFENG FANG, Professor, is with the Key Laboratory of Materials Physics, Institute of Solid State Physics.

Manuscript submitted August 23, 2010.

Article published online February 1, 2011
On the other hand, previous internal friction studies on $\mathrm{Nb}-\mathrm{Mo}-\mathrm{O}^{[7-9]}$ and $\mathrm{Nb}-\mathrm{Ti}-\mathrm{O}^{[7]}$ indicate that $\mathrm{Mo}-\mathrm{O}$ interaction and $\mathrm{Nb}-\mathrm{O}$ interaction show different influences on the Snoek-type relaxations in $\beta$ Ti alloys. It was also confirmed that substitutional solutes of Mo show a beneficial effect on the relative index of relaxation strength of $\mathrm{O}$ (relaxation strength at unit oxygen concentration) in the Nb-based alloys. According to the damping behavior of the designed Ti-Nb-O alloys, ${ }^{[5]}$ lower $\beta$-phase stabilizing element content and lower oxygen content (higher relaxation strength at unit oxygen content) are required in order to make $\beta \mathrm{Ti}$ alloys with oxygen dissolved into advanced high damping alloys. The Ti-Mo-O alloy should be a perspective candidate considering these two conditions.

The $\mathrm{Fe}$ is another effective $\beta$ Ti stabilizer, considering the equivalent Mo content mentioned previously. Moreover, its strengthening potential, ${ }^{[10]}$ low cost, and possible better damping properties compared to other $\beta$ stabilizers suggest a potential substitutional solute. In general, the presence of substitutional solutes may influence the Snoek-type relaxation of the interstitial in bcc metals in various ways including lowering the Snoek peak, suppressing all of the peaks, broadening the Snoek peak, or developing a new peak at a high temperature, due to the interaction of the substitutional and interstitial solute atoms. ${ }^{[11-13]}$ However, in our present research, the interesting finding is that the substitutional solutes of Fe bring an increase of the Snoek peak in the surfaceoxidation-treated Ti-Mo alloys. This may due to the change of the oxidation properties results in the specific distribution of the oxygen, which hence affects the Snoek-type relaxation of the oxygen.

The oxidation of the Ti-Fe alloys was well studied from the aspects of the variation in the microstructure and mechanical properties of the alloys ${ }^{[14,15]}$ and the oxidation kinetics and the mechanism. ${ }^{[16,17]}$ When Ti is 
alloyed with $\mathrm{Fe}$, the strength of interatomic bonds in the Ti matrix lattice decreases, and the redistributions of $\mathrm{Fe}$ in oxidation products influence the growth rates of the oxygen diffusion layer. According to D'yachkov's research, ${ }^{[18]}$ the oxygen diffusion layer of Ti-Fe alloy is shorter than that of the Ti. The reason is that $\mathrm{Fe}$ stabilizes the $\beta$ phase, in which the diffusion rate of oxygen is higher than that in the $\alpha$ phase. ${ }^{[19]}$ On the other hand, Stringer's research indicates that $\mathrm{Fe}$ increases the oxidation rate principally by reducing the time that is necessary for the oxide to lose coherency. ${ }^{[17]}$ Therefore, it is considered that $\mathrm{Fe}$ additions in Ti-Mo alloy may influence the oxidation process considerably, and the different oxygen diffusion layers in the Ti-Mo alloy should result in the varied behavior of Snoek-type damping.

The Ti-Mo and Ti-Mo-Fe alloys with oxygen dissolved were prepared by the atmosphere controlled diffusion process. This process has the advantages of relatively low cost, high rate of treatment, and processing easiness, compared to the conventional method of introducing the interstitial oxygen atoms in titanium alloys during alloy melting. On the other hand, Ti alloys treated by this method possesses a gradient distribution of oxygen, other than the conventionally uniform distribution of oxygen. The Ti alloys with gradient oxygen distribution may exhibit different characters of both the damping behavior and mechanical properties.

In this work, we applied the atmosphere controlled diffusion process to the Ti-15 wt pct $\mathrm{Mo}$ and Ti-15 wt pet Mo-1 wt pet Fe alloys. The effects of Fe addition on the distributions of the alloying components and the Snoek-type damping behavior of the Ti-Mo alloys were investigated.

\section{EXPERIMENTAL PROCEDURE}

The ingots of the Ti-15.3 wt pet Mo and Ti-15.3 wt pet Mo-1.16 wt pct Fe alloys were prepared by the cold crucible levitation melting method. These ingots were hot forged and annealed at $1173 \mathrm{~K}\left(900{ }^{\circ} \mathrm{C}\right)$ for 1 hour, followed by a cold rolling of 80 pct in thickness reduction. Rectangular samples with dimensions of $1 \mathrm{~mm} \times 5 \mathrm{~mm} \times 60 \mathrm{~mm}$ (thickness $\times$ width $\times$ length) were cut off, polished, and pickled by a solution containing 1 pct $\mathrm{HF}$ and 14 pct $\mathrm{HNO}_{3}$. These two kinds of rectangle samples were then subjected to recrystallization annealing at $1073 \mathrm{~K}\left(800^{\circ} \mathrm{C}\right)$ for 1 hour in a quartz tube under a vacuum of less than $0.02 \mathrm{~Pa}$, and denoted hereafter as Ti15Mo and Ti15Mo1Fe, respectively. Then, some of these vacuumannealing-treated samples were subjected to a surface oxidation treatment, which was two-step. The first heating was conducted at $1073 \mathrm{~K}\left(800^{\circ} \mathrm{C}\right)$ for 1 hour in a mixed gas of argon and oxygen, with the flow rate ratio of 10:1. The second heating was vacuum annealing at $1073 \mathrm{~K}\left(800{ }^{\circ} \mathrm{C}\right)$ for 4 hours. Specimens after the surface oxidation treatment are denoted hereafter as Ti15MoO and Ti15Mo1FeO, respectively.

The rectangular samples of Ti15Mo, Ti15MolFe, Ti15MoO, and Til5Mo1FeO were applied for the damping behavior measurement on the dynamic mechanical analyzer (DMA 2980, TA Instruments, Inc., New Castle, DE) in the dual cantilever bending vibration mode. Damping capacities at different vibration frequencies such as $0.4,1.0,2.0,4.0$, and $10.0 \mathrm{~Hz}$ were measured while heating the samples at a heating rate of $2 \mathrm{~K} / \mathrm{min}\left(2{ }^{\circ} \mathrm{C} / \mathrm{min}\right)$.

The microstructure of Ti15MoO and Ti15Mo1FeO was observed by scanning electron microscopy (LEO1550 scanning electron microscope, Carl Zeiss Co., Ltd., Oberkochen, Germany) with energy dispersive spectroscopy and orientation image microscopy accessories. The distribution of molybdenum in the alloys was determined by energy dispersive X-ray spectroscopy. The proportion of $\alpha$ Ti phase in the dual-phase microstructure zone was deduced from the electron backscattered diffraction (EBSD) measurement.

The microhardness distribution profile of the specimen was measured by a micro Vickers hardness tester (MHT-10, Carl Zeiss Co., Ltd.) with a load of $1 \mathrm{~N}$. Oxygen penetration depth was evaluated by the depth of the hardening layer, from the surface to the location where the hardness showed the same value with the matrix unaffected by the oxidation treatment.

\section{RESULTS}

\section{A. Damping Behavior of Til5Mo, Til5MolFe, Ti15MoO, and Ti15MolFeO Alloys}

Figure 1 shows the temperature-dependent variation of damping capacity, tan delta, of Ti-15 wt pet Mo and Ti-15 wt pet Mo-1 wt pct Fe alloys before and after oxidation treatment at various vibration frequencies. The damping peak shifts to higher temperatures with the increased vibration frequency. The frequency dependence of the damping peak is a characteristic of the Snoek-type strain-relaxation process. ${ }^{[20]}$ The activation energies of the Snoek-type relaxation in Ti15Mo and Ti15MoO are 1.29 and $1.33 \mathrm{eV}$, respectively; in Ti15$\mathrm{Mo} 1 \mathrm{Fe}$ and Ti15Mo1FeO, 1.47 and $1.49 \mathrm{eV}$, respectively, are the calculation results of the Arrhenius plot:

$$
\ln (2 \pi f)+\ln \tau_{0}+(H / k) T_{P}^{-1}=0
$$

where $f$ is the vibration frequency, $\tau_{0}$ is the relaxation time at infinite temperature for the strain relaxation process, $H$ is the activation energy, $k$ is the Boltzmann constant, and $T_{P}$ is the peak temperature. The values of $\tau_{0}$ also obtained from the preceding relation are $1.16 \times 10^{-14} \mathrm{~s}$ and $1.0 \times 10^{-16} \mathrm{~s}$ for Ti15Mo and Ti15MoO, respectively, and $4.12 \times 10^{-16} \mathrm{~s}$ and $4.53 \times$ $10^{-16} \mathrm{~s}$ for Ti15Mo1Fe and Ti15Mo1FeO, respectively. These results suggest that the relaxation peaks are induced by the atomic site shift of oxygen atoms.

It is also observed that the background damping level increases considerably at higher temperatures. The increase could be attributed to the presence of dislocations in the microstructure. Oxygen may migrate to unsaturated dislocations and grain boundaries, when it is dissolved in metals with quite small solubility of oxygen. ${ }^{[21]}$ Thus, in the present case, some amount of 


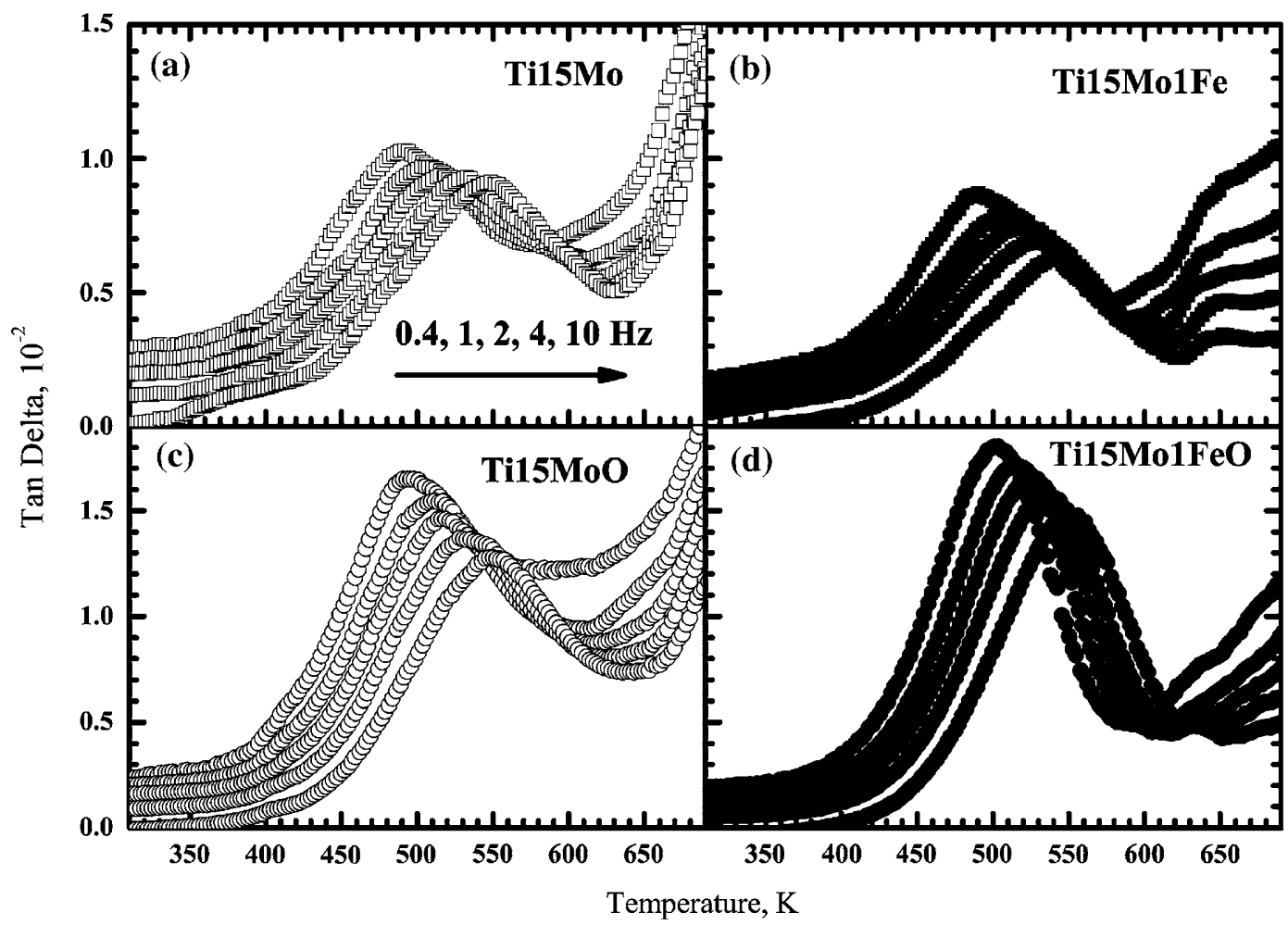

Fig. 1-Damping peaks of the Ti-15 wt pct Mo alloy $(a)$ before and $(c)$ after oxidation treatment, and the Ti-15 wt pct Mo-1 wt pct Fe alloy (b) before and $(d)$ after oxidation treatment at varied frequencies.

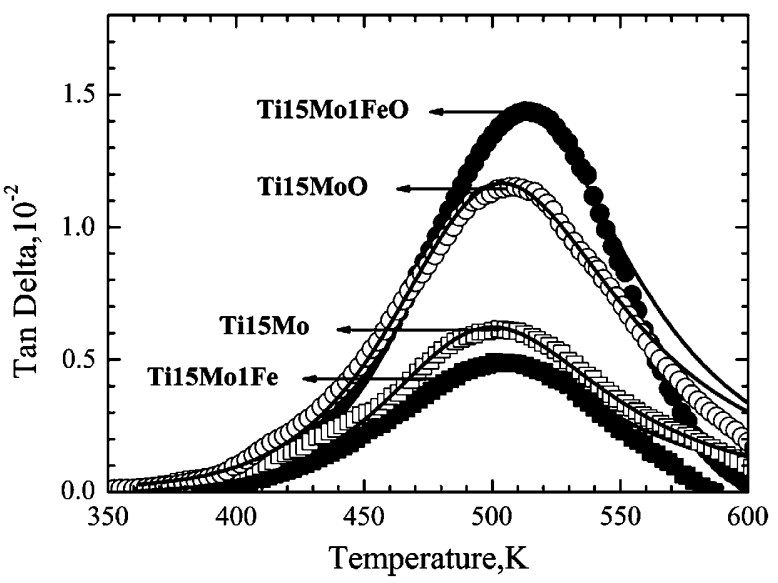

Fig. 2-Background subtracted damping profiles as a function of temperature of the Ti-15 wt pet Mo and Ti-15 wt pet Mo-1wt pet Fe alloys before and after oxidation treatment, measured with frequency of $1 \mathrm{~Hz}$. The peaks were fitted by the Debye curve, as shown in lines.

oxygen is interstitials in the bcc lattice of the Ti alloys, while the others are bound to dislocations and grain boundaries, which are unable to contribute to the observed Snoek-type relaxation peak.

Figure 2 shows the temperature-dependent variation of the damping capacities of the samples at $1 \mathrm{~Hz}$ after the subtraction of background, which is approximated with an enhanced exponential function of temperature. ${ }^{[22]}$ After the oxidation treatment, the damping peaks in both Ti15Mo and Ti15Mo1Fe are increased in the peak height and shifted to higher temperatures, also as shown in Table I. Further, from Figure 2, we can observe that the damping profiles of the alloys can be fitted by the Debye function in a broadened form.

Figure 3 shows the activation energy for the Snoek peaks of oxygen in the present Ti-Mo alloys, plotted as a function of the peak temperature at $1 \mathrm{~Hz}$. Weller ${ }^{[2]}$ summarized the activation energy and peak temperature of the Snoek peak in conventional bcc metals with different interstitial solutes and put forward the approximately linear relation

$$
T_{m}(\mathrm{~K})=362 H(\mathrm{eV})
$$

The present alloys almost fit in with this linear relation. For comparison's sake, the same figure also shows the peak temperature and activation energy of the Snoektype relaxation process obtained from the Ti-Nb-O alloys with oxygen concentration ranging from 0.16 to 3.1 at. pct. The proportionality constant is nearly half that for the binary alloys. ${ }^{[5]}$ The deviations for the Ti-Nb-O alloys from the linear relation may be attributed to the species and concentration of the substitutional solute. The peak temperature and activation energy of $\mathrm{Nb}-\mathrm{O}$ is $422 \mathrm{~K}\left(149^{\circ} \mathrm{C}\right)$ and $1.15 \mathrm{eV}$, respectively, while the corresponding values of Mo-O are higher, about $500 \mathrm{~K}$ $\left(227^{\circ} \mathrm{C}\right)$ and $1.4 \mathrm{eV} \cdot{ }^{[3]}$ However, the present Ti-Mo alloys show less deviation than Ti-Nb-O alloys, indicating that Mo atoms exert a weaker influence on the Ti-O Snoek relaxation than $\mathrm{Nb}$ atoms do, which agrees with the fact that the Mo-O interaction is relatively weak. ${ }^{[7,9]}$ 
Table I. Nominal and Chemical Compositions of the Ti-15 Wt pet Mo and Ti-15 Wt pet Mo-1 Wt pet Fe Alloys before and after Oxidation Treatment, as well as Damping Parameters at $1 \mathrm{~Hz}$

\begin{tabular}{lcccccc}
\hline Alloys & $\begin{array}{c}\text { Owt pct } \\
\text { (At. pct) }\end{array}$ & $\begin{array}{c}\text { Mowt pct } \\
\text { (At. pct) }\end{array}$ & $\begin{array}{c}\text { Fe wt pct } \\
\text { (At. pct) }\end{array}$ & $\begin{array}{c}\text { Activation } \\
\text { Energy }(\mathrm{eV})\end{array}$ & $\begin{array}{c}\text { Peak Temperature } \\
\left(\mathrm{K}\left({ }^{\circ} \mathrm{C}\right)\right)\end{array}$ & Tan Delta $\left(10^{-2}\right)$ \\
\hline Ti15Mo & $0.105(0.34)$ & $15.3(8.3)$ & - & 1.29 & $498(225)$ & 0.62 \\
Ti15MoO & - & $15.4(8.3)$ & - & 1.33 & $505(232)$ & 1.15 \\
Ti15Mo1Fe & $0.092(0.298)$ & $15.3(8.3)$ & $1.16(1.07)$ & 1.47 & $502(229)$ & 0.49 \\
Ti15Mo1FeO & - & $15.6(8.3)$ & $1.17(1.07)$ & 1.49 & $511(238)$ & 1.46 \\
\hline
\end{tabular}

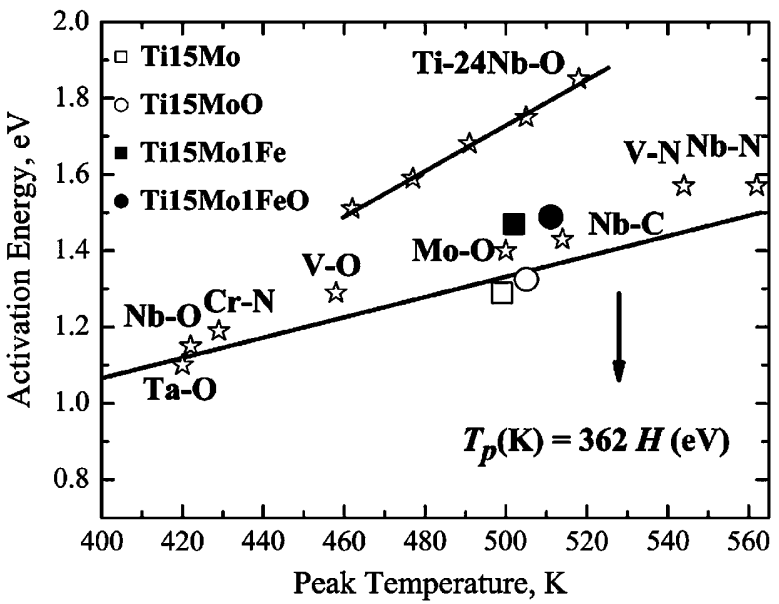

Fig. 3 - Peak temperatures and activation energies of the Snoek-type relaxation peaks in Ti-15 wt pet Mo and Ti-15 wt pet Mo-1 wt pet Fe alloys before and after oxidation treatment, in comparison to the $\mathrm{Ti}-\mathrm{Nb}-\mathrm{O}$ alloys and other published results for bec metals.

\section{B. Microstructure and Composition of the Oxygen Dissolved Zones}

\section{Ti15MoO alloy}

Figure 4 shows the surface microstructure of Ti15$\mathrm{MoO}$ after the surface oxidation treatment observed by SEM and EBSD methods. An oxide zone (about $16 \mu \mathrm{m}$ ) exists in the outmost parts of the specimen, as shown in Figure 4(a). Intimately beneath the oxide zone, the dissolved oxygen induces the formation of small equiaxed $\alpha$ Ti grains in the $\beta$ matrix. Inward to the matrix, the $\alpha$ Ti phase in the form of plates grows both in the $\beta$-phase grains and along the grain boundary. Only the latter $\alpha$ Ti phase exists in the more inward area.

Figure 5 shows the volume fraction of the $\alpha$ Ti phase in the dual-phase zone, analyzed by EBSD measurements, and the microhardness of the gradient microstructure. It is found that the volume fraction of the $\alpha \mathrm{Ti}$ phase decreases remarkably from the surface (beneath the oxide zone) and fades away at the depth of $130 \mu \mathrm{m}$, where the division line between the dual-phase zone ( $\alpha$ Ti and $\beta$ Ti) and the single-phase zone ( $\beta$ phase only) can be determined. Meanwhile, the hardness declines to a steady value at the depth of $400 \mu \mathrm{m}$, where the division line between the single-phase zone (with enriched oxygen) and the matrix can be drawn. With the applied surface treatment condition, three zones are newly formed on the single $\beta$ Ti-phase matrix: the oxide zone $(16 \mu \mathrm{m})$, dual-phase zone $(130 \mu \mathrm{m})$, and oxygenenriched $\beta$-phase zone $(270 \mu \mathrm{m})$, as listed in Table II.

\section{Ti15MoOlFe alloy}

The surface microstructure of Ti15Mo1FeO analyzed with SEM and EBSD methods is shown in Figure 4. The oxide zone of Ti15Mo1FeO is about $1 \mu \mathrm{m}$ in thickness, much thinner than that of Ti $15 \mathrm{MoO}$. Beneath a thin equiaxed $\alpha$ layer, the $\alpha$ Ti grains become larger and tend to develop along the refined $\beta$ Ti-phase grain boundaries as well as in them. Farther from the surface, the plateform $\alpha$ grains form in the $\beta$ Ti-phase grain and become more remote from one another due to the increased difficulty for nucleation. The volume fraction of the $\alpha$ phase is less than that of Ti15MoO, and is depleted in the depth of $92 \mu \mathrm{m}$, as shown in Figure 5. The oxygen penetration depth $370 \mu \mathrm{m}$ derived from the hardness measurement is shallower than that of Ti15MoO. Three zones are also newly formed on the $\beta \mathrm{Ti}$-phase matrix after the surface oxidation treatment: the oxide zone $(1 \mu \mathrm{m})$, dual-phase zone (92 $\mu \mathrm{m})$, and oxygen-enriched $\beta$ phase zone $(278 \mu \mathrm{m})$ for Til5Mo1FeO, as listed in Table II.

It is noted that $\mathrm{Fe}$ plays a primary role in the differences of microstructure between Ti15MoO and Ti15Mo1FeO. The Fe additions increase the oxidation rate principally by reducing the time necessary for the oxide to lose coherency; ${ }^{[17]}$ thus, the oxide zone of Ti15Mo1FeO is much thinner than that of Ti15MoO. The thickness of the $\alpha$-dominant layer is related to the solubility of an alloying element in the hexagonal closepacked lattice of $\mathrm{Ti}$, so the dense equiaxed $\alpha$ layer beneath the oxide zone is thinner in $\mathrm{Ti} 15 \mathrm{Mo} 1 \mathrm{FeO}$ since the solubility of $\mathrm{Fe}$ in $\alpha \mathrm{Ti}$ is still lower than that of Mo in $\alpha \mathrm{Ti}^{[18]}$ The oxygen diffusion depth in Ti15Mo1FeO is shorter than that of Til5MoO, which is in agreement with the proposal that $\mathrm{Fe}$ enhances the rate of oxygen diffusion in Ti-Mo alloys. ${ }^{[18,19]}$

\section{Deduction of Oxygen Contents of the $\beta$ Ti-Phase in the Separate Phase Regions}

\section{Ti15MoO alloy}

The distribution of Mo content in the $\beta$ Ti phase was measured by energy dispersive X-ray spectroscopy. The enrichment of Mo beneath the oxide zone conforms to the works of Glass and Hong ${ }^{[23]}$ and Shida and Anada. ${ }^{[24]}$

The calculated distribution of the oxygen content in the $\beta$ Ti phase was analyzed in separate phase regions. In the dual-phase zone, from the surface (beneath the oxide zone) to the depth of $130 \mu \mathrm{m}$, the oxygen content distribution was calculated based on the Ti-Mo-O ternary phase diagram. ${ }^{[25]}$ In the oxygen-enriched 

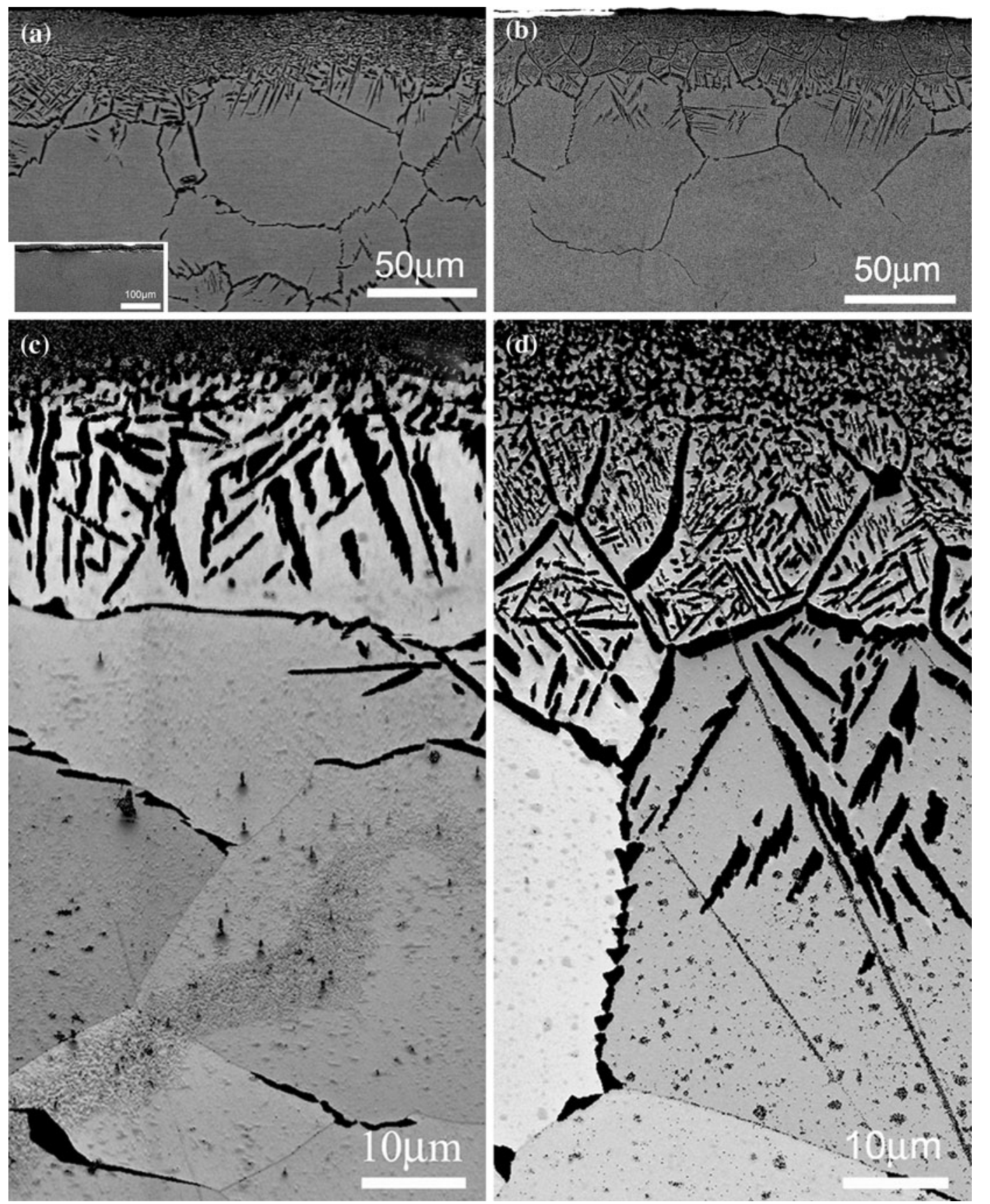

Fig. 4-Microstructure of $(a)$ and $(c)$ Ti15MoO and $(b)$ and $(d)$ Ti15Mo1FeO. The subsurface microstructure measured by (a) and (b) SEM and (c) and (d) EBSD.

$\beta$-phase zone, from the depth of 130 to $400 \mu \mathrm{m}$, the oxygen distribution was analyzed by the unidirectional diffusion function with the semi-infinite solid model, based on Fick's second law shown in the following:

$$
C_{x}=C_{0}+\left(C_{130}-C_{0}\right) \operatorname{erfc}\left(\frac{x-130}{2 \sqrt{D_{1} t}}\right)
$$

where $x$ is the depth from the surface (beneath the oxide zone); $C_{x}$ is the concentration at the depth of $x$ from the surface; and $C_{130}$ is the concentration in the depth of
$130 \mu \mathrm{m}$, which is assumed to be invariant. Since the oxide zone was maintained throughout the oxidation treatment, $C_{0}$ is the concentration in the base material, $0.105 \mathrm{wt}$ pct; $D_{1}$ is the diffusion coefficient; and $t$ is the time, 4 hours. The boundary conditions are $C_{x}=C_{130}$ at $x=130$ and $C_{x}=C_{0}$ at $x=400$, which determine the values of the diffusion coefficient $D_{1}$ as $2.5 \times 10^{-13} \mathrm{~m}^{2} \mathrm{~s}^{-1}$. This value is comparable to the linear extrapolated result from the work of Wasilewski and Kehl, ${ }^{[26]}(0.5$ to 6.6$) \times 10^{-13} \mathrm{~m}^{2} \mathrm{~s}^{-1}$ at $1073 \mathrm{~K}$ $\left(800{ }^{\circ} \mathrm{C}\right)$. 


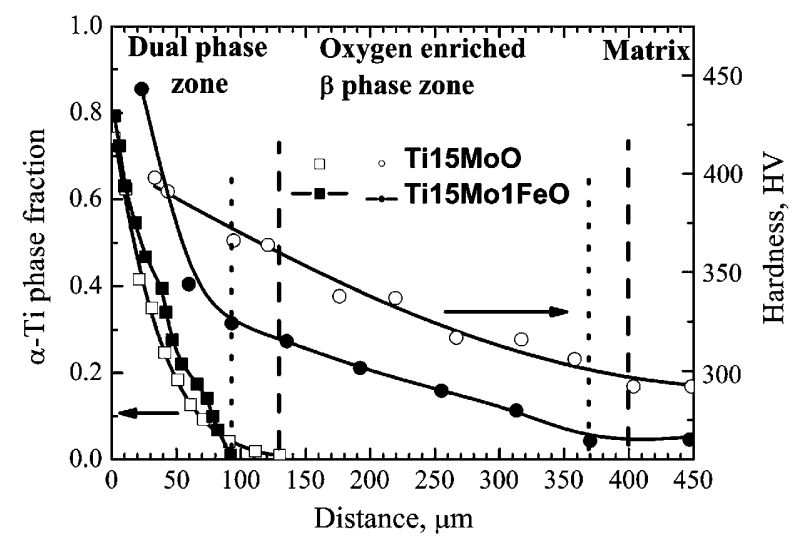

Fig. 5-Volume fraction of the $\alpha \mathrm{Ti}$ in the dual-phase zone and the hardness profiles of Ti15MoO and Ti15MolFeO. The dash lines and dot lines are dividing lines of Ti15MoO and Ti15MolFeO, respectively.

Table II. Main Parameters of the Partitions Divided According to the Oxygen Distribution

\begin{tabular}{lccc}
\hline & $\begin{array}{c}\text { Oxide } \\
\text { Zone } \\
(\mu \mathrm{m})\end{array}$ & $\begin{array}{c}\text { Dual-Phase } \\
\text { Zone } \\
(\mu \mathrm{m})\end{array}$ & $\begin{array}{c}\text { Oxygen-Enriched } \\
\beta \text {-Phase Zone }(\mu \mathrm{m})\end{array}$ \\
Alloys & 16 & 130 & 270 \\
Ti15MoO & 1 & 92 & 278 \\
\hline
\end{tabular}

\section{Ti15MolFeO alloy}

The enrichment of $\mathrm{Fe}$, as well as Mo, beneath the oxide zone conforms to the investigation results of Stringer. ${ }^{[27]}$ The enrichment of $\mathrm{Fe}$ in the surface layer of Ti15Mo1FeO shields oxygen diffusion, resulting in the reduction of the oxide as well as the oxygen penetration depth compared to that of Ti15MoO. The ternary phase equilibrium of the Fe-Mo-Ti system shows that the Ti-15 wt pet Mo- 1 wt pet Fe alloys fall into the $\beta$ Ti area without the TiFe compounds. ${ }^{[28]}$

The distribution of oxygen in $\mathrm{Ti} 15 \mathrm{Mo} 1 \mathrm{FeO}$ was analyzed in the same way as that for Til5MoO. However, the equivalent amounts of $\beta$-stabilizer in weight percent were quantified by the values of $\mathrm{Mo}_{\mathrm{eq}}$, that is, $\mathrm{Mo}_{\mathrm{eq}}$ (mass pct) $\left.=1.0 \mathrm{Mo}+2.9 \mathrm{Fe}+\cdots \cdot{ }^{6}\right]$ Figure 6 shows the distribution of the $\mathrm{Mo}_{e q}$ as well as the calculated oxygen content distribution in the $\beta \mathrm{Ti}$ phase. The diffusion coefficient in the oxygen-enriched $\beta$-phase zone is $2.1 \times 10^{-13} \mathrm{~m}^{2} \mathrm{~s}^{-1}$, as in the calculation result by the diffusion equation mentioned previously. The coefficient is smaller than that of Ti15MoO, $2.5 \times 10^{-13} \mathrm{~m}^{2} \mathrm{~s}^{-1}$. It is reasonable to consider that $\mathrm{Fe}$ atoms are prone to be enriched in the surface layer and, thus, shield oxygen diffusion. ${ }^{[18]}$

3. Comparison of oxygen distributions in the $\beta$ phase of Ti15MoO and Ti15MolFeO alloys

Table II lists the main parameters of the oxygendiffused surface region of the two alloys. From Figure 6, we can find that, in Til5MoO, the oxygen content decreases extensively from the surface to a depth of about $100 \mu \mathrm{m}$, while in $\mathrm{Ti} 15 \mathrm{Mo} 1 \mathrm{FeO}$, the oxygen content is higher and spread deeper than the

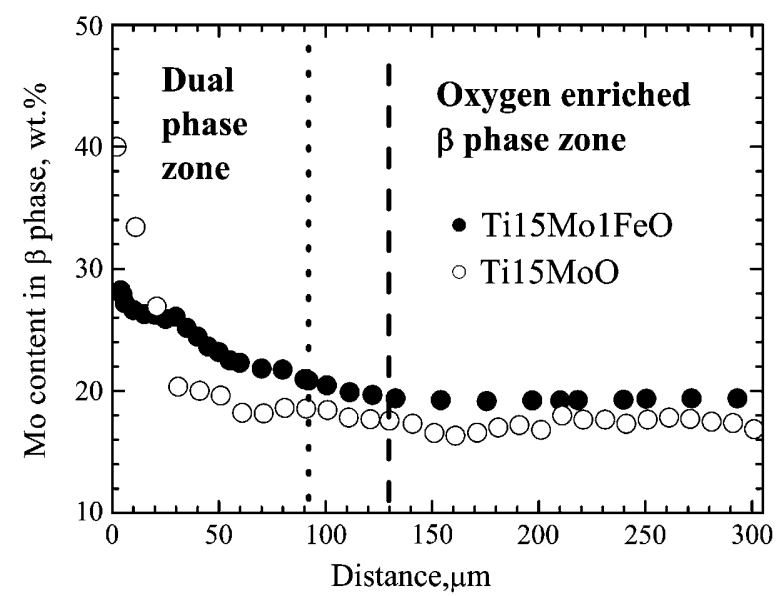

(a)

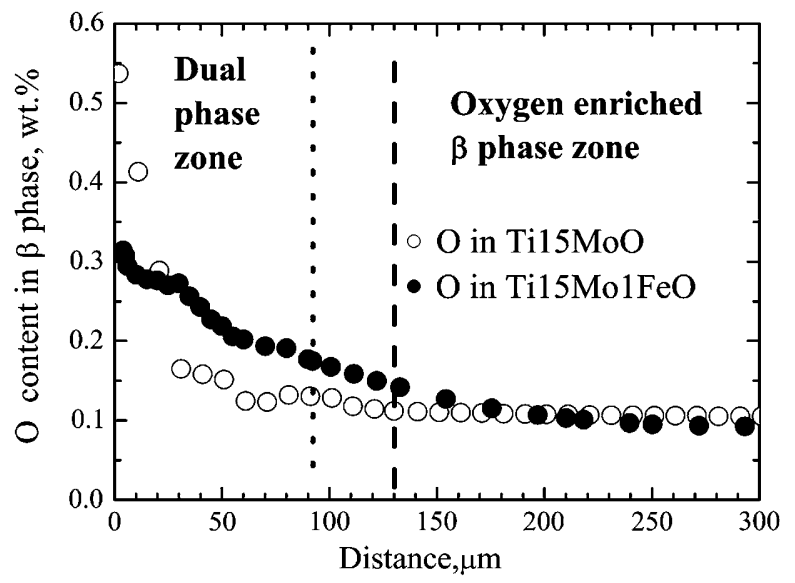

(b)

Fig. 6- (a) Measured distribution of molybdenum (equivalent) in the $\beta$ phase of Ti15MoO and Ti15Mo1FeO alloys. (b) The calculated distribution of oxygen. The dash lines and dot lines are dividing lines of Ti15MoO and Ti15MolFeO, respectively.

corresponding parts of Ti15MoO. The volume fraction of $\alpha$ Ti phase in the Ti15Mo1FeO alloy is higher than that in the Ti15MoO alloy, though the depth of dual phase is a bit shorter, as shown in Figure 5.

The strength of Snoek-type relaxation is relevant to the direction of the stress applied to the crystal lattice, the dissolve element concentration, the temperature, the grain size of a polycrystal, and the substitutional atoms, which influence the Snoek-type relaxation via substituteinterstitial $(s-i)$ interaction. In the present research, the addition of 1 wt pet Fe into the Ti-15 wt pet Mo alloy brings in an increase of the strength of Snoek-type relaxation. The influence of substitutional atom $\mathrm{Fe}$ will be analyzed in the discussion part.

\section{DISCUSSION}

\section{A. Influence of Substitute-Interstitial Interaction on the Snoek-Type Damping Peak}

Up to now, the influence of substitutes on the Snoektype peak has been summarized in terms of the $s-i$ 
interaction, which leads to a change in the diffusion activation energy of dissolved interstitial atoms located near the relatively immobile substitutional atoms. Two types of $s-i$ interaction are considered to affect the Snoek relaxation: short-range type in the case of a strong chemical interaction and long-range type in the case of an elastic interaction. ${ }^{[3]}$

The attractive interaction between $\mathrm{O}$ and $\mathrm{Fe}$ is supposed to reduce the number of oxygen atoms in the free interstitial sites, and thus lower the Snoek-type peak in Ti15MoFeO, considering the energies of maximum attraction of interstitial and substitutional atoms in the $\mathrm{Nb}-(\mathrm{Ti}, \mathrm{Mo}, \mathrm{Fe})-\mathrm{O}$ alloys are as follows: $0.17 \mathrm{eV}$ for Ti-O, $0.056 \mathrm{eV}$ for Mo-O, and $0.157 \mathrm{eV}$ for Fe-O. ${ }^{[11]}$ Therefore, a chemical interaction cannot account for the heightening of the Snoek-type peak in Ti-Mo alloys.

On the other hand, size factor, i.e., the difference in atomic size between the solute and solvent atoms, has been studied to reveal its influence on the extent of the $s-i$ interactions by Hansson and Arsenault ${ }^{[29]}$ and Szkopiak and Smith. ${ }^{[7]}$ Recently, Saitoh et al. ${ }^{[30]}$ proposed that the linear size factor, i.e., the ratio of change in the lattice spacing by the additional atom, is closely related to the Snoek-type peak height. The difference in atomic size between the substitutional atoms and solvent atoms gives rise to elastic strain field, which dominates the reduction of the Snoek peak height. As for the present Ti-based alloy, since $\mathrm{Fe}$ (with the linear size factor -22.59) distorts the lattice in a more pronounced way than Mo (with the linear size factor -7.64), ${ }^{[31]}$ the reduction rate of the Snoek peak height by the substitutional atom of $\mathrm{Fe}$ should be more than that of Mo. Therefore, the influence of the elastic strain could not account for the rise of the Snoek-type peak height of Ti15MolFeO compared to Ti15MoO.

\section{B. Influence of Distribution of Oxygen on the Snoek-Type Peak}

The oxidation property of Fe influences the oxidation process of the Ti-Mo alloy, which can be related to the observed improvement of the Snoek-type damping. As shown in Figure 4, the morphology of the surfaceoxidation-treated Ti15MoO and Ti15Mo1FeO is similar, while the lengths of the dual-phase zone and oxygenenriched-phase zone are different separately, suggesting a difference in the oxygen distribution between them, as seen in Figures 5 and 6. The oxygen distribution from the surface to the basis in Ti15MolFeO is more gradual and generally higher than in Ti15MoO. The inhomogeneous distribution of oxygen as well as the distribution of the strain during the measurement of damping capacity will be taken into consideration.

The surface-oxidation-treated alloys were analyzed based on the law of mixtures for internal friction, in order to investigate the contribution of the oxygen dissolved layer to the total damping capacity. In terms of the fractional energy dissipation per cycle, the damping capacity of the oxidation-treated alloy consisting of an oxygen-dissolved zone and a matrix can be given by

$$
Q_{T}^{-1}=\frac{1}{2 \pi} \frac{\Delta W}{W}=\frac{1}{2 \pi} \frac{\Delta W_{M}+\Delta W_{O}}{W_{M}+W_{O}}
$$

where $\Delta W$ is the dissipated energy per cycle and $W$ the strain energy stored at maximum deflection. The suffixes $T, M$, and $O$ refer to total, matrix, and the oxygen dissolved zone, respectively. The internal frictions in the matrix and the oxygen dissolved zone are

$$
Q_{M}^{-1}=\frac{1}{2 \pi} \frac{\Delta W_{M}}{W_{M}} \text { and } Q_{0}^{-1}=\frac{1}{2 \pi} \frac{\Delta W_{O}}{W_{O}}
$$

Combining Eqs. [4] and [5] gives

$$
Q_{T}^{-1}=\frac{W_{M}}{W_{M}+W_{O}} Q_{M}^{-1}+\frac{W_{O}}{W_{M}+W_{O}} Q_{O}^{-1}
$$

Considering the sample measured undergoes an inhomogeneous strain condition during the dual cantilever vibration, and the strain energy is expressed as

$$
W=\frac{1}{2} E \iiint \varepsilon^{2} d x d y d z
$$

where $E$ is the Young's modulus and $\varepsilon$ is the strain amplitude. The strain amplitude $\varepsilon$ as a function of position can be written in the form ${ }^{[32]}$

$$
\begin{aligned}
\varepsilon(x, y, z)= & \varepsilon_{\max } \frac{2 y}{d} * 0.164 \\
& *(\cosh \alpha \cos (2 \alpha z / L)-\cos \alpha \cosh (2 \alpha z / L))
\end{aligned}
$$

where $\alpha$ is 2.365 for the fundamental mode of vibration, $\varepsilon_{\max }$ is the maximum strain amplitude, $y$ is the distance from the neutral plane in the thickness direction, $z$ is in the length direction, $L$ is the length of the sample, and $d$ is the thickness.

Combining Eqs. [7] and [8] and providing $E_{M} \approx E_{\mathrm{O}}$ gives

$$
\frac{W_{O}}{W_{M}}=\frac{\int_{O} \varepsilon^{2}(y) d y}{\int_{M} \varepsilon^{2}(y) d y}=\frac{\int_{h_{M} / 2}^{h_{M} 2+h_{O}} \frac{4 y^{2}}{d^{2}} d y}{\int_{O}^{h_{M} 2} \frac{4 y^{2}}{d^{2}} d y}=6 r+12 r^{2}+8 r^{3}
$$

where $h_{M}$ and $h_{O}$ are the thickness of the matrix and the oxygen dissolved zone on one side, respectively, and $r$ is the relative thickness $h_{O} / h_{M}$.

Combining Eqs. [6] and [9] gives

$Q_{T}^{-1}=\frac{1}{6 r+12 r^{2}+8 r^{3}+1} Q_{M}^{-1}+\frac{6 r+12 r^{2}+8 r^{3}}{6 r+12 r^{2}+8 r^{3}+1} Q_{O}^{-1}$

Equation [10] makes it feasible to express the damping effectiveness of a surface oxygen dissolved zone, as shown in Figure 7. The relative damping, i.e., the ratio of the damping of the total to that of the oxygen dissolved zone per unit oxygen content, is approximately proportional to the thickness of the oxygen-dissolved zone, within the bulk of the oxygen-dissolved zone. 


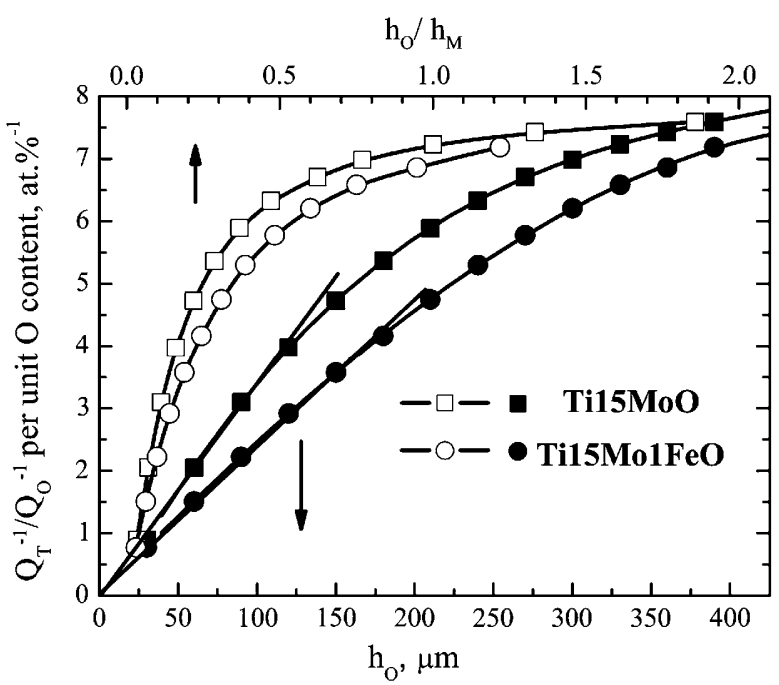

Fig. 7-Relative damping plotted to the thickness of the oxygen dissolved zone and the relative thickness.

The thickness of the bulk of the oxygen-dissolved zone is about $100 \mu \mathrm{m}$ from the surface to the matrix in Ti15MoO and is about $150 \mu \mathrm{m}$ in Ti15Mo1Fe, as shown in Figure 6(b). In addition, Figure 7 also illustrates that the relative damping increases dramatically with increasing relative thickness (the ratio of the thickness of the oxygen dissolved zone to that of the basis), restricting the bulk of the oxygen dissolved zone. The approximate linear relations are useful as a guide in scaling, suggesting that a thicker oxygen dissolved zone is related to a higher damping. The proportionality factor in Ti15Mo1FeO, $2.41 \times 10^{4}$ at. $\mathrm{pct}^{-1} \mathrm{~m}^{-1}$, is lower than in Ti15MoO, $3.34 \times 10^{4}$ at. $\mathrm{pct}^{-1} \mathrm{~m}^{-1}$. This is conformable to the suppressive effect of the substitutional atoms on the Snoek-type relaxation, due to the $s-i$ interaction. On the other hand, the length of the bulk oxygen dissolved zone in $\mathrm{Ti} 15 \mathrm{Mo} 1 \mathrm{FeO}$ is longer than that in Ti15MoO, and moreover, the oxygen concentration in the oxygen dissolved zone of Til $5 \mathrm{MolFeO}$ is apparently higher than that of TilsMoO, due to the modified oxygen diffusion performance by the addition of $\mathrm{Fe}$ atoms. Consequently, the damping capacity of Ti15Mo1FeO improves compared to that of Ti15MoO.

\section{CONCLUSIONS}

1. Surface oxidation treatment was conducted for Ti-15 wt pet Mo and Ti-15 wt pet Mo-1 wt pet Fe alloys at $1073 \mathrm{~K}\left(800{ }^{\circ} \mathrm{C}\right)$. The obtained Ti15Mo1FeO exhibited higher Snoek-type relaxation peak compared to that of Til5MoO.

2. Three new zones, the oxide zone, dual-phase zone, and oxygen-enriched $\beta$ phase zone, formed on the single $\beta$ Ti-phase matrix after the oxidation treatment for the Ti-15 wt pet Mo and Ti-15 wt pct Mo-1 wt pet $\mathrm{Fe}$ alloys. A simple diffusion model was developed to predict the oxygen distribution.
3. The relative damping is approximately proportional to the thickness of the oxygen dissolved zone. Compared to Ti15MoO, Ti15Mo1FeO possesses a thicker oxygen dissolved zone and a higher oxygen concentration in this zone due to the substitutional solute of $\mathrm{Fe}$, and thus a higher Snoek-type relaxation peak.

\section{REFERENCES}

1. C.A. Wert: J. Phys. Chem. Solids, 1970, vol. 31, pp. 1771-83.

2. M. Weller: Mater. Sci. Eng. A, 2006, vol. 442, pp. 21-30.

3. M.S. Blanter, I.S. Golovin, H. Neuhäuser, and H.-R. Sinning: Internal Friction in Metallic Materials - a Handbook, Springer, Berlin, 2007.

4. F. Yin, S. Iwasaki, D. Ping, and K. Nagai: Adv. Mater., 2006, vol. 18, pp. 1541-44.

5. F. Yin, L. Yu, and D. Ping: Mater. Sci. Eng. A, 2009, vols. 521522 , pp. $372-75$.

6. R. Boyer, G. Welsch, and E.W. Collings: Materials Properties Handbook: Titanium Alloys, The Materials Information Society, ASM INTERNATIONAL, Materials Park, OH, 1994.

7. Z.C. Szkopiak and J.T. Smith: J. Phys. D, 1975, vol. 8, pp. $1273-$ 84.

8. E. Miura, K. Ota, K. Yoshimi, and S. Hanada: Phil. Mag., 2003, vol. 83 , pp. 2343-57.

9. N.P. Kushnareva and S.E. Snejko: J. Alloys Compd., 1994, vols. 211-212, pp. 75-79.

10. D.J. Lin, J.H.C. Lin, and C.P. Ju: Biomaterials, 2002, vol. 23, pp. $1723-30$

11. M.S. Blanter and M.Y. Fradkov: Acta Metall. Mater., 1992, vol. 40 , pp. $2201-08$.

12. H. Numakura and M. Koiwa: in M3d: Mechanics and Mechanisms of Material Damping, ASTM STP 1304, A. Wolfenden and V.K. Kinra, eds., West Conshohocken, PA, 1997, pp. 383-93.

13. R. Cantelli and Z. Szkopiak: Appl. Phys. A, 1976, vol. 9, pp. 15360 .

14. H.W. Worner: J. Inst. Met., 1951, vol. 79, pp. 173-88.

15. N.P. Allen, T.H. Schofield, and B. Mellish: J. Inst. Met., 1954, vol. 82 , pp. $534-38$

16. V.I. D'Yachkov: Russ. J. Appl. Chem., 2003, vol. 76, pp. 1025-30.

17. J. Stringer: J. Inst. Met., 1962, vol. 90, pp. 298-303.

18. V.I. D'yachkov: Russ. J. Appl. Chem., 1998, vol. 71, pp. 1869-74.

19. C.J. Rosa: Metall. Trans., 1970, vol. 1, pp. 2517-22.

20. R. De Batist: Internal Friction and Structural Defects in Crystalline Solids, North-Holland, Amsterdam, 1972.

21. A.R. Rosenfield: Nature, 1963, vol. 198, pp. 279-80.

22. A.S. Nowick and B.S. Berry: Anelastic Relaxation in Crystalline Solids, Academic Press, New York, NY, 1972.

23. R.S. Glass and Y.K. Hong: Electrochim. Acta, 1984, vol. 29, pp. $1465-70$

24. Y. Shida and H. Anada: Mater. Trans., JIM, 1994, vol. 35, pp. 623-31.

25. P.A. Farrar, L.P. Stone, and H. Margolin: Trans. Am. Inst. Min. Metall. Eng., 1956, vol. 206, pp. 595-600.

26. R.J. Wasilewski and G.L. Kehl: J. Inst. Met., 1954, vol. 83, pp. 94 104.

27. J. Stringer, M.G. Cowgill, and N.C. Griffiths: Nature, 1960, vol. 185 , p. 304

28. V. Raghavan: J. Phase Equilib., 2003, vol. 24, pp. 182-83.

29. D.F. Hasson and R.J. Arsenault: J. Less-Common Met., 1972, vol. 27 , pp. $417-18$

30. H. Saitoh, N. Yoshinaga, and K. Ushioda: Acta Mater., 2004, vol. 52, pp. 1255-61.

31. H.W. King: J. Mater. Sci., 1966, vol. 1, pp. 79-90.

32. S. Asano: Jpn. J. Appl. Phys., 1969, vol. 8, pp. 539-44. 